\title{
Review \\ Impact of UAV Hardware Options on Bridge Inspection Mission Capabilities
}

\author{
Zahra Ameli ${ }^{1, *}$, Yugandhar Aremanda ${ }^{2} \mathbb{D}$, Wilhelm A. Friess ${ }^{2}$ and Eric N. Landis ${ }^{1} \mathbb{D}$ \\ 1 Department of Civil and Environmental Engineering, University of Maine, Orono, ME 04469, USA; \\ landis@maine.edu \\ 2 Department of Mechanical Engineering, University of Maine, Orono, ME 04469, USA; \\ yugandhar.aremanda@maine.edu (Y.A.); wilhelm.friess@maine.edu (W.A.F.) \\ * Correspondence: zahra.ameli@maine.edu; Tel.: +1-(216)-303-0503
}

Citation: Ameli, Z.; Aremanda, Y.; Friess, W.A.; Landis, E.N. Impact of UAV Hardware Options on Bridge Inspection Mission Capabilities.

Drones 2022, 6, 64. https://doi.org/ $10.3390 /$ drones 6030064

Academic Editor: Fahim Ullah

Received: 11 February 2022

Accepted: 25 February 2022

Published: 28 February 2022

Publisher's Note: MDPI stays neutral with regard to jurisdictional claims in published maps and institutional affiliations.

Copyright: (C) 2022 by the authors. Licensee MDPI, Basel, Switzerland. This article is an open access article distributed under the terms and conditions of the Creative Commons Attribution (CC BY) license (https:// creativecommons.org/licenses/by/ $4.0 /)$.

\begin{abstract}
Uncrewed Aerial Vehicles (UAV) constitute a rapidly evolving technology field that is becoming more accessible and capable of supplementing, expanding, and even replacing some traditionally manual bridge inspections. Given the classification of the bridge inspection types as initial, routine, in-depth, damage, special, and fracture critical members, specific UAV mission requirements can be developed, and their suitability for UAV application examined. Results of a review of 23 applications of UAVs in bridge inspections indicate that mission sensor and payload needs dictate the UAV configuration and size, resulting in quadcopter configurations being most suitable for visual camera inspections (43\% of visual inspections use quadcopters), and hexa- and octocopter configurations being more suitable for higher payload hyperspectral, multispectral, and Light Detection and Ranging (LiDAR) inspections (13\%). In addition, the number of motors and size of the aircraft are the primary drivers in the cost of the vehicle. $75 \%$ of vehicles rely on GPS for navigation, and none of them are capable of contact inspections. Factors that limit the use of UAVs in bridge inspections include the UAV endurance, the capability of navigation in GPS deprived environments, the stability in confined spaces in close proximity to structural elements, and the cost. Current research trends in UAV technologies address some of these limitations, such as obstacle detection and avoidance methods, autonomous flight path planning and optimization, and UAV hardware optimization for specific mission requirements.
\end{abstract}

Keywords: bridge inspection; UAV hardware optimization; payload; flight time; remote sensing; damage detection

\section{Introduction}

The aging and degradation of civil and industrial infrastructures have posed a notable public safety threat [1]. Bridges are subjected to deterioration due to aging, as well as corrosion, fatigue of materials, extreme environmental loads, and unexpected impacts. As a result, damage to the bridge superstructure or substructure may occur, such as cracking, delamination, cross-section loss, foundation settlement, and others [2]. Monitoring infrastructure and preventive maintenance save money and continue to grow in importance as bridges age [3]. According to the Federal Highway Administration (FHWA), of the over 619,600 bridges in the United States [4-6], more than 43,000 are in poor condition [7]. Figure 1 shows the percentage of the United States bridges in each timeframe and the bridges' condition over time based on the latest annual report published by FHWA in 2021. The plot suggests gradual but consistent improvement of bridge conditions over time, but still more than $50 \%$ of the bridges are more than 40 years old, and more than $60 \%$ of them are in fair and poor condition and need efficient preventative maintenance to extend the life, minimize cost, and protect the safety of the public. Thus, the inspection and assessment of these infrastructures are essential for the early detection of possible complications with minimum interruption in operation [8]. 


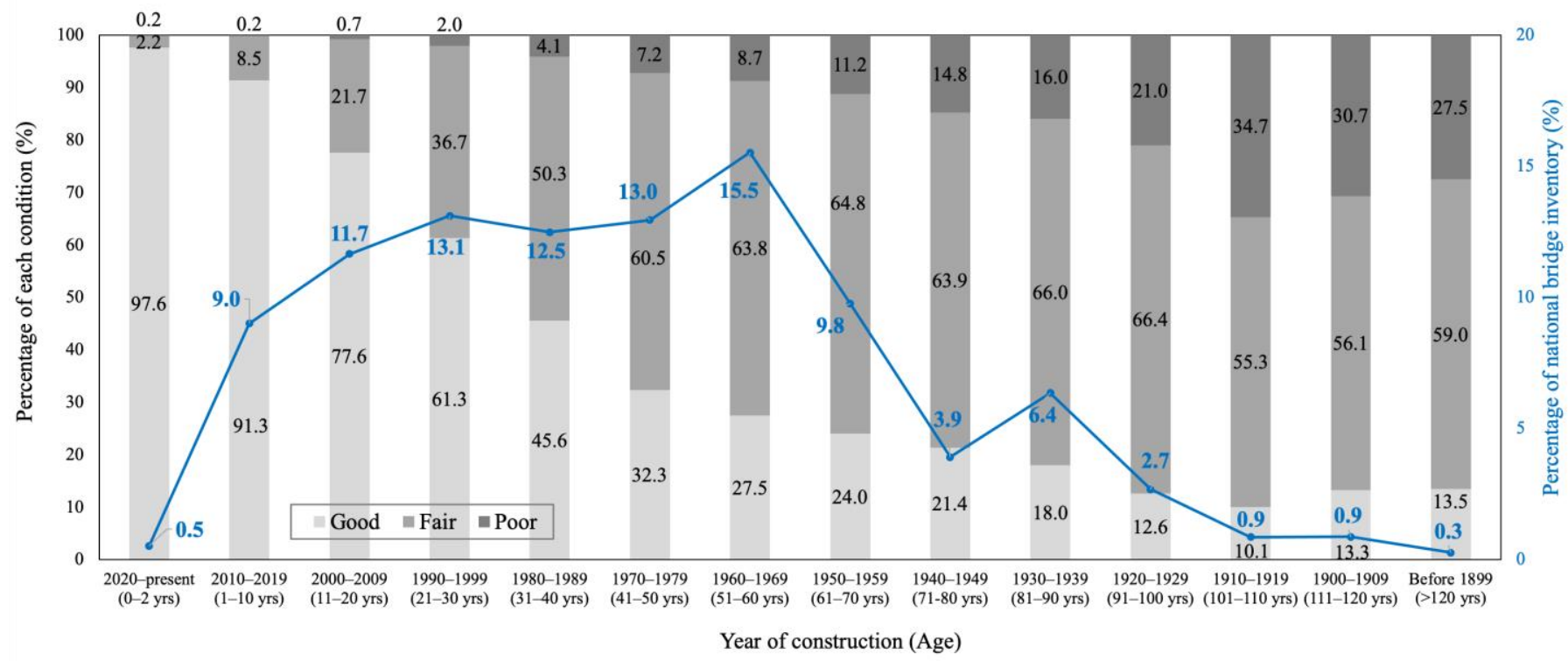

Figure 1. Condition assessment of the bridges in the United States based on the last published data in 2021.

Currently, visual inspection is the main procedure for bridge inspection. It might take a few hours and might extend to several days of work in a typical bridge. Visual inspection is usually completed using simple equipment such as hammer sounding and chain dragging for detecting surface defects. During the inspection, the inspector evaluates the overall condition of the bridge and identifies locations where a more detailed inspection is required. The inspector usually takes photos while assessing the bridge's condition, records observations, and fills out a report. The report summarizes the inspector's findings regarding deteriorated areas, defect locations, and a condition rating of inspected elements. Additional investigations may be recommended if the inspector feels a need. Due to the lack of a generic framework to generate quantitative results, results obtained from visual inspection rely on the inspector's experience.

One of the attempts to overcome drawbacks of visual inspection is the use of Nondestructive Testing or Techniques (NDT). NDT techniques are currently used as a supplemental procedure for visual inspection if needed or when performing in-depth inspection [9]. These techniques include electrical resistivity (ER), ground-penetrating radar (GPR), chloride-ion penetration test (CIP), impact echo (IE), infrared thermography (IT), radiography testing (RT), linear polarization (LP), and half-cell potential (HCP) which usually are used for concrete bridges and acoustic emission (AE), ultrasonic testing (UT), liquid penetrant testing (PT), magnetic particle testing (MT), computed tomography (CT), and eddy current testing (ET) for steel bridges [10].

Unfortunately, visual and NDT-based bridge inspections are associated with certain limitations. They are expensive, cause high logistical efforts, and can even interfere with the operational conditions of infrastructure [11-14]. Also, the quality of the collected data during inspections can be significantly affected by the inspectors' training and qualifications, and the number of inspectors conducting the inspection [10]. Due to the aforementioned reasons, traditional manual inspection can no longer completely satisfy the requirements of practical engineering. For example, the recently built rigid frame bridges, Hezhangte Bridge and Sanshui River Bridge in China, whose piers are as high as $180 \mathrm{~m}$, present a challenge to bridge managers, as it is very difficult to conduct on-site manual inspection on such bridge piers [15]. Therefore, novel inspection and maintenance of infrastructure approaches are highly interesting [16].

UAVs have emerged as a viable and promising option to facilitate and expand bridge inspection activity and overcome the challenges of conventional bridge inspection [17-21]. Their use can both expedite current visual-based inspections and enable more advanced 
multi-sensor approaches [22]. UAV technology and sensor integration is a rapidly developing area, and matching the appropriate UAV to a particular bridge inspection scheme requires several considerations and can represent a challenge.

While the literature already has some excellent reviews on the topic (as detailed below), in this work, we seek to better match mission objectives to hardware and, in doing so, present current opportunities and limitations. This paper reviews current bridge inspection practices along with current research on the application of UAVs for bridge inspections. The advantages and limitations of UAV application in various bridge inspections are evaluated, and requirements for a successful bridge inspection mission are identified and linked to the UAV configuration options. Section 2 presents the types of bridge inspection, and Section 3 reviews developments of UAVs in bridge inspection. In Section 4, applications of UAV mounted sensors in bridge inspection are investigated, and bridge inspection relevant UAV hardware is discussed in Section 5. UAV hardware characteristics related to bridge inspection applications are evaluated in Section 6, and finally, limitations and opportunities are discussed in Section 7.

\section{Types of Bridge Inspection}

According to the National Bridge Inspection Standards (NBIS, 2004), there are eight types of bridge inspection: inventory, routine, damage, in-depth, fracture critical member, hands-on, special, and underwater inspection [23]. A summary of the inspection types and their scope and mission is presented in Table 1.

Table 1. Bridge inspection types and scope.

\begin{tabular}{|c|c|}
\hline Inspection Type & Scope and Mission \\
\hline \multirow{2}{*}{$\begin{array}{c}\text { Initial } \\
\text { (inventory) }\end{array}$} & $\begin{array}{l}\text { Provide all Structure Inventory and Appraisal (SI\&A) data and determine } \\
\text { baseline structural conditions and load capacity ratings }\end{array}$ \\
\hline & - $\quad 3 \mathrm{D}$ model construction \\
\hline \multirow{2}{*}{ Routine } & $\begin{array}{l}\text { Evaluate physical and functional condition of structure and ensure that } \\
\text { service requirements are satisfied }\end{array}$ \\
\hline & $\begin{array}{l}-\quad \text { Defect detection } \\
\text { - } \quad \text { 3D model reconstruction }\end{array}$ \\
\hline \multirow[b]{2}{*}{ In-depth } & $\begin{array}{l}\text { Hands-on inspection to determine deficiencies not detectable by } \\
\text { routine inspection }\end{array}$ \\
\hline & $\begin{array}{ll}\text { - } & \text { Fatigue crack detection } \\
\text { - } & \text { Surface crack detection } \\
\text { - } & \text { Corrosion detection }\end{array}$ \\
\hline \multirow{2}{*}{ Damage } & $\begin{array}{l}\text { Determine if a bridge requires load restrictions or closures or the extent of } \\
\text { repair required. }\end{array}$ \\
\hline & $\begin{array}{ll}\text { - } & \text { Surface crack detection } \\
\text { - } & \text { Fatigue crack detection }\end{array}$ \\
\hline Special & $\begin{array}{l}\text { Intended to monitor a known or suspected deficiency at a specific location } \\
\text { - } \quad \text { Surface crack detection } \\
\text { - } \quad \text { Fatigue crack detection } \\
\text { - } \quad \text { Corrosion detection }\end{array}$ \\
\hline $\begin{array}{c}\text { Fracture critical } \\
\text { member }\end{array}$ & $\begin{array}{l}\text { A detailed hands-on inspection to detect cracks. } \\
\text { - } \quad \text { Surface crack detection } \\
\text { - } \quad \text { Fatigue crack detection }\end{array}$ \\
\hline
\end{tabular}

As is shown in Table 1, an initial (inventory) inspection is a preliminary inspection performed prior to entering service to determine baseline structural conditions. It is a fully documented investigation and is accompanied by load capacity ratings. Routine inspection is the most common type of inspection, and for almost all bridges, it is required 
by FHWA at regular intervals of less than 24 months so that inspectors can monitor defects and deterioration. Routine inspections evaluate the physical and functional condition of the structure, including all elements of the bridge superstructure, deck underside, and substructure that are accessible from the ground [24]. During routine inspections, a qualified bridge inspector records the degree of damage for each bridge element, following an element numbering system and a checklist. In-depth inspection is a close-up inspection of one or more structural members to detect any deficiencies not readily visible using routine inspection procedures. This inspection may include a load rating to assess the residual capacity of the member or members, depending on the extent of the deterioration or damage. Damage inspections should be performed due to collision, fire, flood, significant environmental changes, or loss of structural support. If major damage has occurred, inspectors must evaluate fractured members, section loss, make measurements for the misalignment of members, and check for any loss of foundation support [25]. Special inspections are used to monitor known or suspected deficiencies such as foundation settlement or scour, fatigue damage, or the public's use of a load posted bridge. Special inspections are usually not comprehensive enough to meet the requirements of routine inspections [24]. Fracture critical inspection is a hands-on (within arm's length of the component) inspection of a fracture critical member or member components. It may include visual and other nondestructive evaluation. This may require that critical areas be specially cleaned prior to the inspection and additional lighting be used.

\section{Developments of UAVs in Bridge Inspection in the US}

Due to rapid advancements in UAV technology in recent years, in the US, Departments of Transportations (DOTs) have shown increasing interest in the use of UAV for bridge inspections [26]. In 2008, California DOT (Caltrans) [27] and the University of California at Davis designed a custom twin-motor, single-duct UAV to be tethered to the ground, making it easier to control and conform to the FAA regulations at the time. The objective of Caltrans was to construct an "Aerobot" to easily access structural components at high altitudes, such as girders [28]. Caltrans terminated the project as it did not result in a fully deployable aerial vehicle due to its instability in the wind and the unsuccessful performance of an altitude holder sensor.

Wisconsin DOT [29] used two different UAVs for evaluating damage conditions specific to each of the three roadway bridges, including two steel girder bridges and one steel truss bridge. They learned that quality of the UAV equipment is important for bridge inspections since the results quality is tied to the resolution of the images and the ability to view the bridge elements from proper angles. Idaho Transportation Department [30] researched the use of UAVs in under-bridge inspections for detecting fatigue cracking. The conclusion of the experiments was that detecting fatigue cracking and other bridge defects by using visual spectrum and thermal image processing is feasible, but requires a careful selection of UAS platforms, on-board avionics, and data collection sensors [31].

Michigan DOT (MDOT) [32] has conducted tests of UAVs for bridge inspections since April 2015. Images taken with a UAV were used to detect deficiencies in bridge decking for potholes and wear, and involved the use of RGB cameras and infrared and LiDAR sensors. The studies demonstrated that using UAV increases safety and reduces inspection costs. It was also found that simultaneous use of different sensors can significantly improve the accuracy of collected data. Oregon DOT (ODOT) [33] conducted a statewide study on UAV applications for bridge inspections. Wind condition was found to be the most important environmental variable in operating UAV close to bridges, while ambient light conditions and camera settings are critical to obtaining high-quality imagery. The ability to articulate a camera in any direction with a zoom lens and employ an onboard camera-assistant spotlight was the most useful technical feature for collecting visual data. The use of a UAV was most effective for initial and routine inspections and less effective for more complex in-depth inspections that require touching, probing, or scraping a bridge. 
Minnesota DOT (MnDOT) [34] performed one of the most comprehensive studies evaluating UAVs' application and effectiveness in bridge inspections. In the first phase (2015), the research team learned that UAVs capable of pointing cameras upward and operating without GPS have better performance for bridge inspection applications. In the second phase (2017), the research team expanded the demonstration to different structure types and sizes using a SenseFly Albris UAV. They concluded that this vehicle is flexible to control, and its operational capabilities are not diminished by the loss of GPS signals. In the third phase (2018), 39 bridges including a wide range of sizes, types, and locations are inspected using SenseFly Albris and Flyability Elios UAVs (a quadcopter enclosed in a spherical wireframe cage to avoid collision damage/specialized in performing indoor inspections by utilizing computer vision-based navigation). They learned that easy piloting, access to confined areas, and cost-effectiveness are the benefits, whereas short battery life, video interference due to the cage and air flow, and debris are the limitations of this specific type of drone. It was also found that UAV platforms equipped with thermal sensors can effectively detect concrete delamination. The study recommended using UAV for routine inspections where hands-on inspection is not required. Another recommendation relates to the use of UAV equipped with sophisticated collision avoidance systems as well as the use of collision-tolerant platforms which can operate in direct contact with the bridge structure.

UMass research team [35] developed and tested practical procedures and protocols to guide MassDOT in integrating UAV technologies into bridge inspections. It was determined that selection of the proper types of UAV platforms and sensors are the primary factors that affect the success of UAV integration into the bridge inspections. Kansas DOT (KDOT), in collaboration with the Kansas State University Transportation Center, studied the potential of UAV implementation within KDOT. They found out there is a need to handle large and overwhelming volumes of collected data [36]. Nebraska DOT (NDOT) conducted a study on UAV applications in bridge inspection program. The NDOT study concluded that except fracture critical bridge inspections, all other types of bridge inspections could incorporate UAV [37].

North Carolina DOT (NCDOT) partnered with North Carolina State University to evaluate the potential benefits of UAV for transportation applications. The conclusion of the study indicates that the major factors affecting success of UAV missions include weather, sensor capabilities, flight planning, software processing, and ground control point design and placement [38]. Vermont Agency of Transportation (VTrans) tested UAV capabilities for bridge inspections. It was noted that significant increases in the volume of data collected with the help of UAV may create additional challenges for data storage and processing. It was also found that photogrammetry can successfully replace LiDAR in the generation of accurate 3D models for lower cost [39]. Most common types of UAVs which state DOTs have used for bridge inspection purposes are shown in Table 2.

Table 2. Most frequently used UAVs within state DOTs for bridge inspection purposes.

\begin{tabular}{|c|c|c|c|}
\hline DJI Inspire & Topcon Falcon 8 & 3DR Iris & DJI Mavic \\
\hline $\begin{array}{c}\text { Wisconsin DOT [29], } \\
\text { Nebraska [37], } \\
\text { North Carolina [38] }\end{array}$ & $\begin{array}{l}\text { Wisconsin DOT [29], } \\
\text { Kentucky }\end{array}$ & Idaho DOT [40] & Idaho DOT [40] \\
\hline
\end{tabular}


Table 2. Cont.

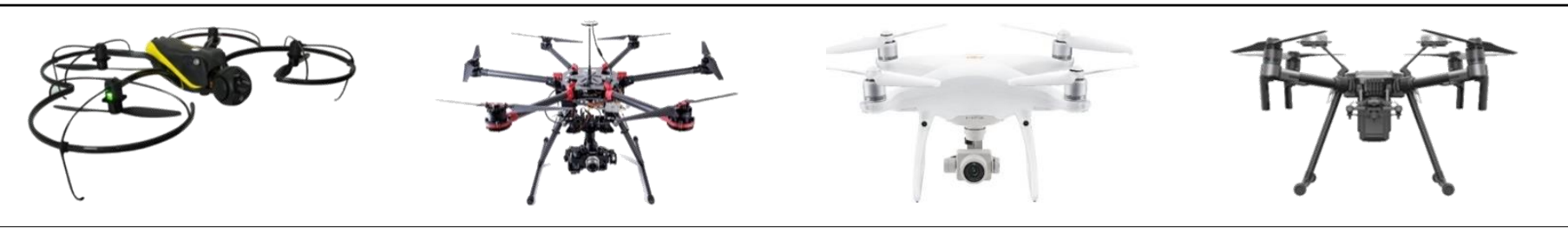

\begin{tabular}{cccc}
\hline SenseFly albris & DJI S900 & DJI Phantom & DJI M210 RTK \\
\hline $\begin{array}{c}\text { Oregon DOT [33], Vermont } \\
\text { [39], Minnesota DOT [34] }\end{array}$ & Oregon DOT [33] & Oregon DOT [33], & Alaska [41], Massachusets \\
[35], Vermont [39] & South Carolina [42] \\
\hline
\end{tabular}
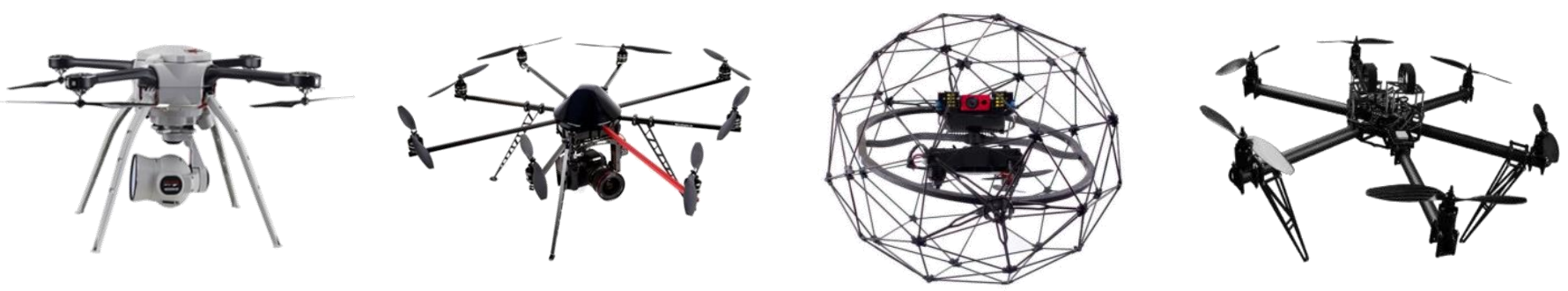

\begin{tabular}{cccc}
\hline Aeryon SkyRanger & Mikrocopter Hex & Flyability Elios & Cinestar \\
\hline Minnesota DOT [34] & North Carolina [38] & Minnesota DOT [34] & Norht Carolina [38] \\
\hline
\end{tabular}

There are numerous ongoing research programs to eliminate current limitations and address the needs in the application of UAVs in bridge inspection. These include handling large volumes of collected data, environmental conditions affecting the quality of images, navigation and flight stability in areas with poor GPS signals and around large steel structures, collision avoidance capabilities and image processing, and advanced computational methods to detect/evaluate deck deficiencies. A few of these studies are summarized in this section.

To analyze the effectiveness of drones as supplemental bridge inspection tools and facilitate bridge inspection, researchers have conducted numerous studies. Junwon Seo et al. (2018) [43] performed an analysis of the effectiveness of drone-based bridge inspection. They used a DJI Phantom 4 quadcopter to inspect a bridge. The drone was able to identify various damage types, including cracks, spalling, corrosion, and moisture on the bridge. During the conduction of the study, some limitations were identified, including high wind speeds, camera overexposure, low illumination, and flight challenges due to obstacles in an enclosed section (e.g., between closely spaced girders). S. Sankarsrinivasan et al. [44] proposed a novel complete field mapping protocol using UAVs to enable their real-time health monitoring. This method integrates data captured by a UAV to identify cracks and assess surface degradation using grayscale thresholding. They used a custom-built hexacopter with a payload capacity of $110 \mathrm{~g}$ and a $20 \mathrm{~min}$ flight time. Yunas Zewdu Ayele (2020) [45] proposed a methodology for a UAV-based bridge inspection to assess bridge damage using novel technologies. Their methodology for bridge inspection involves collecting data and training a model which enables modifying drone flights to obtain optimum efficiency. The data gathered from the previous stage is built into 3D models to capture the element geometry of every bridge asset to use for navigational and controlling purposes. Chen et al. (2016) [46] developed a hexacopter with an upward gimbal that can capture upward imagery and accommodate additional attachments such as an ultrasonic sensor, laser scanner, and LiDAR. They learned that position estimation using a laser scanner can only work in the specific bridge environment, and it is still a problem without GPS when the environment is much more complex. To fly in a more complex environment, other localization methods need to be integrated into the system to get a more precise position to control the drone's flight. D. Roca et al. [47] used a Mikrokopter Okto XL 
octocopter for inspecting outdoor building facades. This UAV has a Kinect sensor mounted unit capable of acquiring geometric data in 3D, which can then be reproduced as a 3D model to evaluate potential damages. HekmatiAthar et al. (2020) [48] introduced a hierarchical multiple-criteria decision making framework for UAV-enabled bridge inspection selection practices. The initiated framework employed a hierarchical method to analyze 32 criteria categorized in flight performance, situational awareness, payload and sensor capabilities and communication quality.

Even with advances in UAV technology, manual piloting remains a challenge, and developing navigation and autonomous flight capabilities are of growing interest. For example, Yu et al. 2019 [12] presented a LiDAR-based approach for autonomous navigation using 2D LiDAR scanning. Bolourian et al. (2020) [49] proposed an optimized path planning technique for a UAV-based LiDAR scanner that performs bridge inspections. This technique uses genetic algorithms for solving the traveling salesman problem of potential locations of bridge cracks with an objective of minimum flight time and maximum visibility. Jung et al. 2020 [50] addressed a hierarchical graph-based simultaneous localization and mapping (SLAM) method for fully autonomous bridge inspection using an aerial vehicle. They concluded that even with accurate position estimation under a bridge, the risk of UAV collision significantly increases when a wind gust of over $10 \mathrm{~m} / \mathrm{s}$ suddenly occurs.

The ability to convert images or video data into actionable information automatically and robustly remains challenging. Vision-based approaches, in conjunction with cameras and UAVs, offer the potential for rapid and automated inspection and monitoring for bridge condition assessment [51]. Sutanu Bhowmick et al. [52] concluded that UAVs with real-time vision sensing are more efficient in terms of time and resources. They used pixel segmentation to identify whether a particular pixel belonged to a crack or not. Krisada Chaiyasarn et al. [53] developed a convolutional neural network (CNN) based image crack detection method for inspecting historical structures using feature extraction. The data is captured using a DJI Phantom UAV. Saleem et al. 2020 [14] proposed instant crack damage detection using an image capturing and geo-tagging system with a CNN for automated inspection. The damages extracted by the CNN are instantly transformed into a global bridge damage map, with georeferencing data acquired using image capturing and geotagging. To overcome the limitation of visual inspection in terms of post-processing big data to develop a 3D model, a UAV-based real-time autonomous crack detection algorithm was proposed by Morgenthal et al. [11]. This system includes machine learning-based feature detection of target areas that provides crack information to the team instantly while capturing data.

The application of infrared thermography (IRT) techniques has been demonstrated in several research projects. Omar et al. (2017) [54] demonstrated the applicability of UAVmounted thermal cameras for quantitative measurements of delamination in RC bridge decks. Image analysis based on the k-means clustering technique was utilized to segment the mosaic and identify objective thresholds. Mac et al. 2019 [55] considered simultaneously using the results from the handheld IR camera, and the IR camera mounted on a UAV. They found out that there is a strong correlation between the size and detectable depth of delamination. Hiasa et al. 2017 [56] presented a methodology that combines numerical modeling and IRT data to improve the usability and efficiency of data analysis, possibly leading to automated analysis and evaluation. To obtain thresholds for data processing, finite element model simulation was utilized. Washer et al. (2010) [57] presented results from a study of the effect of solar loading on the detection of embedded targets in a large concrete block. The effect of the depth of the embedded target is discussed, as well as the timing of inspection (relative to sunrise) that resulted in maximum contrast in thermal images. Ellenberg et al. 2016 [58] demonstrated the capability of UAVs equipped with both color and IR cameras to rapidly and effectively detect and estimate the size of regions where subsurface delamination exists. Shen et al. (2020) [59] suggested that IRT technology could be a complementary method to evaluate the delamination of concrete bridge decks in addition to the existing chain dragging method currently used by the Nebraska Department 
of Transportation (NDOT). They mentioned some common pitfalls such as dark asphalt smears on the concrete deck, wet deck surface, and excessive dirt covering the deck surface that must be avoided during the survey.

Ongoing research that addresses the limitations of GPS-based UAV navigation relies on computer vision approaches to seek and avoid obstacles and optimize the flight path. Youn et al. [60] created a real-time surrounding map for the UAV navigation in a GPS denied environment with the integration of an error state Kalman filter and an open-sourced SLAM (simultaneous localization and mapping) algorithm. To achieve flight control and reachability, a nonlinear observer control technique can be implemented to guide the UAV [61]. This system uses an onboard UAV sensor suite and a visual camera to identify a target with as low as four feature points and compare them with a preprogrammed feature data library. Based on the feature identified, the UAV takes the necessary position and velocity corrections autonomously without a pilot command [62]. Flightpath optimization is another major aspect of infrastructure inspection and can be achieved using novel optimization techniques, such as particle swarm optimization [63].

Custom-made UAVs have gained considerable attention to address the current limitations of off-the-shelf vehicles. Whitley et al. (2020) [17] presented a solution to the current limitations in the implementation of UAVs which are reliance on a skilled operator and/or the requirement for a UAV to operate in a cluttered, GPS-denied environment. They utilized commercial off-the-shelf hardware, including laser rangefinders, optical flow sensors, and live video telemetry. González-deSantos et al. 2020 [64] presented a new payload to perform contact inspection in large structures using UAV. The payload has been designed to be independent of the flight controller. The payload approaches the structure slowly and avoids bounces during the first touch. This sensor measures the thickness of metal sheets when in contact with it. Myeong et al. 2015 [65] demonstrated the use of wall-climbing UAVs that can fly and stick on walls to perform inspections. Kocel et al. [66] developed a UAV payload with a combination of a long probe and a transducer that contacts the surface and moves along with the UAV for a thorough inspection. They developed a robust flight control system to maintain minimal distance from the inspecting surface, a major requirement for this UAV technology.

\section{Various Applications of UAV Mounted Sensors in Bridge Evaluation}

- Surface crack detection: The majority of literature papers have addressed crack detection as the primary application of UAVs in bridge inspection [67]. The imagebased surface crack assessment method consists of two main steps. The first step is crack detection, which intends to eliminate noise and extract crack objects from the images. The second step of crack assessment is the extraction of crack edges and calculating crack parameters, including crack width and length [15]. To detect bridge surface cracks, RGB cameras are typically used. The UAVs can capture high-quality images from hard-to-reach areas of the bridge $[6,67]$ using optical cameras, but the distance from the structure surface, illumination condition, wind, and the minimum number of the required images are important considerations that need to be taken into account.

- Delamination: The horizontal debonding in the subsurface of the deck, known as deck delamination, often indicates the corrosion-induced deterioration of the deck reinforcement [68]. For the task of delamination profiling through thermography, the existing challenges are the shape and the depth of delamination, environmental factors such as air temperature and solar intensity, which introduces the feature variation of the same delamination, surface textures such as cracks, color difference, patching, and road painting, which adds external noise [69]. Image processing techniques were developed to extract temperature abnormalities automatically, quantitatively, accurately, and sensitively. This process mainly utilizes threshold temperature values and temperature gradients. The first challenge is determining threshold values because the values are affected by environmental conditions. The second challenge is difficulty 
in evaluating the entire target object by one global threshold value. The reason may be that the entire surfaces of infrastructures or buildings are not under the same conditions, and each local area has a different average temperature and gradient [70].

- Corrosion: Corrosion is a natural phenomenon involving an electrochemical process liberating a positive charge that becomes a stable compound. Although some corrosion occurs on the subsurface metal materials, such as the steel reinforcement used in concrete for bridges, a large amount of corrosion happens on the surface of steel bridges [71]. RGB and IRT cameras are commonly used for corrosion detection [72,73]. Infrared Thermography is a promising method of corrosion detection, measurement, and mapping, but more research needs to be done to perfect this method for use in the field [74].

- $\quad$ Fatigue: Fatigue cracks are very difficult to see and may have lengths shorter than $7 \mathrm{~mm}$ and widths narrower than $0.1 \mathrm{~mm}$. Fatigue cracks normally appear in the superstructure near large cross frames, welded stiffeners, or other complex geometries, making access difficult. To detect fatigue cracks, RGB and IRT cameras are usually used [30]. Careful selection of a UAV platform, environmental conditions, and lighting conditions are important factors that affect UAV-based fatigue crack detection [75].

- 3D model reconstruction: To help bridge managers visualize the geometric information (e.g., damage location) and surface condition (e.g., damage type and extent) of an existing structure, 3D models of the structures are constructed to establish a base onto which damage information can be referenced. RGB cameras and LiDAR sensors can be implemented to generate 3D models [76]. In contrast to LiDAR, which usually contains more 3D points, photogrammetry uses a collection of 2D images taken from various angles and locations around the structure to create 3D points. Because photogrammetry matches image features to create the $3 \mathrm{D}$ points, there is a significant computational expense and less accuracy than LiDAR. However, the only equipment required for photogrammetry is an optical sensor, while UAV-based LiDAR systems require expensive LiDAR sensors and GPS systems, which decreases battery life by adding additional payload to the system [77].

\section{Overview of Bridge Inspection Relevant UAV Hardware}

\subsection{Aircraft and Payloads}

The typical UAV is composed of a frame, motors, control unit, onboard sensors, communication system, and power supply. Many UAVs display a dual tube substructure to facilitate the installation of different payloads [67]. A higher payload capacity results in additional sensor carrying capability, albeit often by trading off flight time. UAV performance requirements related to flights in close proximity to the bridge structure (e.g., turbulent flow characteristics around the bridge) and terrain characteristics (e.g., surface roughness, temperature, and humidity) have made the selection of the suitable UAV platform and sensors a challenging problem [48]. This includes positioning and navigating the UAV around or under bridges (GPS-denied operations) [46,78-81] and platform stability (in windy conditions where turbulence and other aerodynamic phenomena make for unpredictable wind effects) $[49,82,83]$. Achieving a balance between payload capability, endurance, vehicle stability, and navigation capabilities represent the primary challenges when optimizing the UAV for bridge inspections.

Vertical takeoff and landing capability and the ability to hover in place during flight, an enhanced ability to fly close to structures while maintaining a fixed, safe standoff distance, a stabilizing gimbal that can alter the camera pointing angle to any vertical angle, and a camera equipped with an optical zoom for capturing high-resolution imagery while at a safe standoff distance represent parameters and vehicle characteristics suitable for bridge inspections [33]. 


\subsection{Payload Packages and Mission Classifications}

Flight time, mission requirements, payload capacities of the UAV, and navigation requirements are important considerations that affect the selection of appropriate sensors for bridge inspection. Various types of UAV-based sensors and their potential application are summarized in Table 3.

Table 3. Various applications and appropriate detection sensors.

\begin{tabular}{|c|c|c|}
\hline Sensor (Typical Weight) & Mission & $\begin{array}{l}\text { Sample UAV Used/Maximum } \\
\text { Published Endurance }\end{array}$ \\
\hline Visual camera $(0.1-1 \mathrm{~kg})$ & $\begin{array}{l}\text { - } \quad \text { Surface crack detection (e.g., } \\
\text { Corrosion, Fatigue, delamination) } \\
\text { - } \quad \text { 3D-model }\end{array}$ & - $\quad$ DJI Phantom 4 pro (30 min) [40] \\
\hline IRT camera $(0.2-1.5 \mathrm{~kg})$ & $\begin{array}{l}\text { - Surface and subsurface deficiencies } \\
\text { detection (e.g., Fatigue, Delamination) }\end{array}$ & - $\quad$ Sensefly Albris (22 min) [33,39] \\
\hline LiDAR sensors (1.3-2.8 kg) & - $\quad 3 \mathrm{D}$ point cloud model & - $\quad$ Altus LRX (22 min) [84] \\
\hline Synthetic aperture radar (SAR) (2.7 kg) & - $\quad$ Surface crack detection & - $\quad$ Spreading Wings S1000 (15 min) [85] \\
\hline Hyperspectral and multispectral $(0.8-2 \mathrm{~kg})$ & - $\quad$ Surface crack detection & - $\quad$ Aeryon Skyranger (40 min) [34] \\
\hline
\end{tabular}

\section{UAV Hardware Characteristics Related to Bridge Inspection Applications}

To identify the relationship between UAV hardware characteristics and bridge inspection missions, a list of commercially available drones was gathered from the literature. A total of 23 UAVs are used by various state DOTs in the United States, and their primary performance specifications, including Gross Takeoff Weight (GTW), endurance limit, payload capacity, type of payloads, and physical size of the aircraft, are gathered and compared. This data is then used to analyze how the aforementioned factors influence the selection of a UAV for bridge inspection missions.

Bridge inspections rely on multirotor sensor platforms due to their vertical takeoff and landing (VTOL) ability, scalability, versatility in accommodating various payloads, and wide range of commercial availability. The data gathered in this review reflects that $50 \%$ of the UAVs are quadcopters, 39\% hexacopters, and 20\% octocopters. Quadcopters used by the state DOTs are DJI Mavic [40], Flyability Elios-2 [34], Skyranger R70 [34], Sensefly Albris $[33,34,39]$. They were used in missions to inspect surface and fatigue cracks, corrosion, and to capture visual images of bridge structures for 3D model reconstruction. A DJI Phantom 4 pro with thermal IR camera payload was used by Alaska DOT to inspect bridge decks and girders to perform damage inspection [41]. Flyability Elios-2 is a specialized quadcopter developed to perform confined space inspections using robust vision-based navigation and acquire usable data in low light conditions [86]. The Selection of a proper UAV for bridge inspection missions depends on the payload requirements as shown in Table 3. UAVs can be categorized based on this payload capacity that typically ranges from $350 \mathrm{~g}$ to $4200 \mathrm{~g}$ as illustrated in Figure 2. 


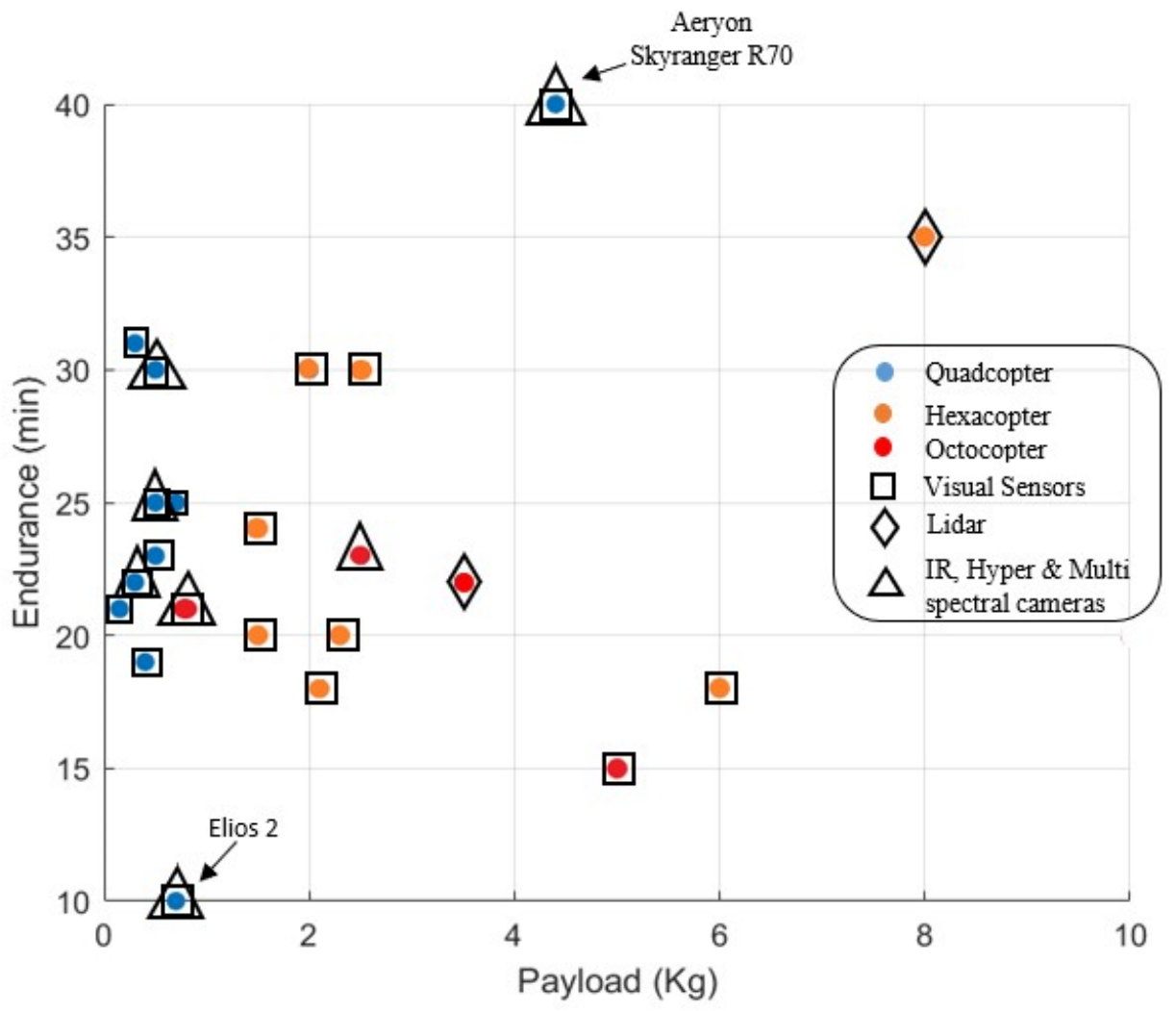

Figure 2. UAV Payload (Kg) vs. Endurance (min).

The UAVs are distinguished by their motor configuration (quadcopters, hexacopter, and octocopter) and the type of sensor (visual sensors, LiDAR, IR, Hyper- and Multispectral camera) which they carry for a specific bridge inspection mission. As seen in Figure 2, UAVs with payload capacities of less than $1 \mathrm{~kg}$ are primarily quadcopters, with hexacopters and octocopters displaying payload capabilities ranging from $2 \mathrm{~kg}$ to $8 \mathrm{~kg}$. Quadcopters with a low payload range typically carry RGB and IR camera sensors to perform visual and thermal inspections. The DJI Mavic, which falls into a low payload capacity quadcopter category, has shown superior performance in GPS denied missions involving fatigue crack detection [30]. The larger hexacopters and octocopters multirotor UAVs, with their higher payload capacity and increased diagonal size, can carry heavier sensors such as LiDAR scanners and interferometric synthetic aperture radars (InSAR). Hexacopters like Intel Falcon 8+ [86], DJI M600, and S900 [33] combined with sensors like Velodyne LiDAR or Zenmuse gimbals have been used to inspect bridges. There are some exceptional quadcopters with a payload range similar to hexacopters and octocopters. One of such quadcopters is the Skyranger R70 which has a $4.4 \mathrm{~kg}$ of payload capacity and was used in the LiDAR mission for the MNDOT [34].

From Figure 2, it is clear that the payload capacities and the number of rotors do not significantly affect endurance. Although a substantial fraction of quadcopters have higher endurance than hexacopters and octocopters, their payload is still limited. Figure 2 shows that the typical endurance of UAVs used for the bridge inspection ranges from 20 to $30 \mathrm{~min}$, although some hexacopter and octocopter UAVs display a reduced endurance due to their size and higher payload capacity.

The number of motors and size of the aircraft are the primary drivers in the cost of the vehicles. Figure 3 shows the cost of the UAV versus its payload capacity. It is clear that an increase in the number of motors increases the cost of the UAV. Among all listed drones, 7 quadcopters fall under the USD 1000 price range, whereas 3 are in the range of USD 2000 to USD 3500. Finally, a quadcopter Aeryon Skyranger R70 [86] is an expensive UAV that can perform semi-autonomous flight assisted by object detection and classification 
algorithms for navigation. This aircraft navigation system uses four vision cameras for accurate positioning of the aircraft, making it more expensive than the other UAVs.

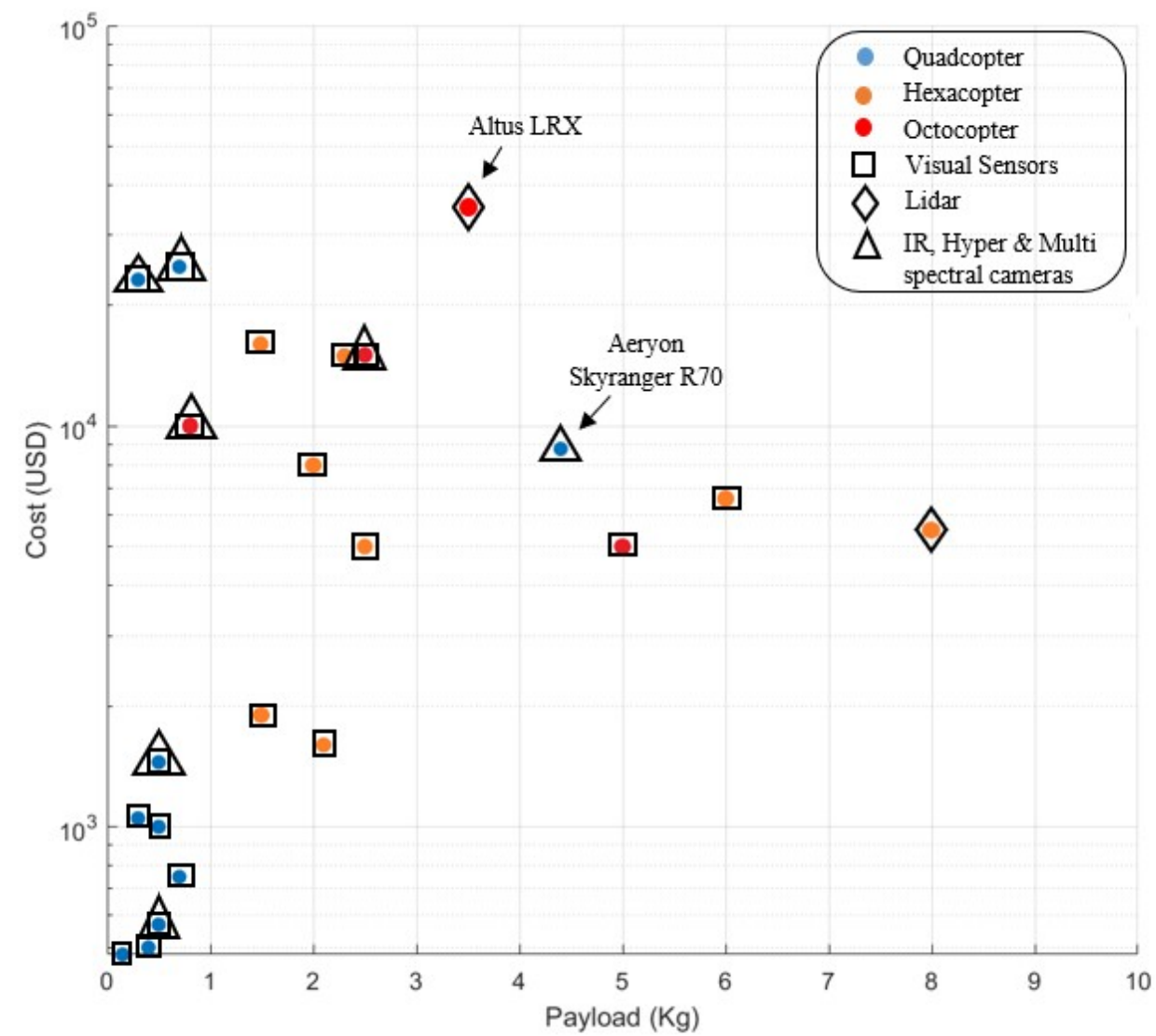

Figure 3. UAV Payload (Kg) vs. cost (USD).

UAVs that carry heavier LiDAR and SAR sensors fall in the range of USD 5000 to USD 19,000 , the cost range of the listed hexacopters and octocopters. It is worth noting that most quadcopters such as Sensefly Albris and Flyability Elios 2 have a similar price range compared to hexacopters. In summary, the primary factors that affect the cost of a UAV and its size and motor configuration are the additional technologies it incorporates to perform a specified mission.

The type of payload that a UAV can carry primarily depends on its size. Figure 4 illustrates the relationship between UAV's payload and their diagonal distance between motors (frame size). The trend shows that a higher payload capacity needs a large frame to accommodate the increased sensor weight. About $63 \%$ of the quadcopters fall between diagonal sizes of $300 \mathrm{~mm}$ to $600 \mathrm{~mm}$ and can carry less than a $1 \mathrm{~kg}$ payload. M600 and Inspire flight 1200 are two hexacopters with high payload capacities of $6 \mathrm{~kg}$ and $8 \mathrm{~kg}$, respectively. M600 is primarily designed to perform industrial aerial photography, whereas the IF1200 is designed to carry a Yellowscan VX20 LiDAR scanner. Altus LRX is an octacopter with a LiDAR scanner and has a maximum payload capacity of $3.5 \mathrm{~kg}$. UAVs with lower payloads are smaller in size, and a majority of them are quadcopters. 


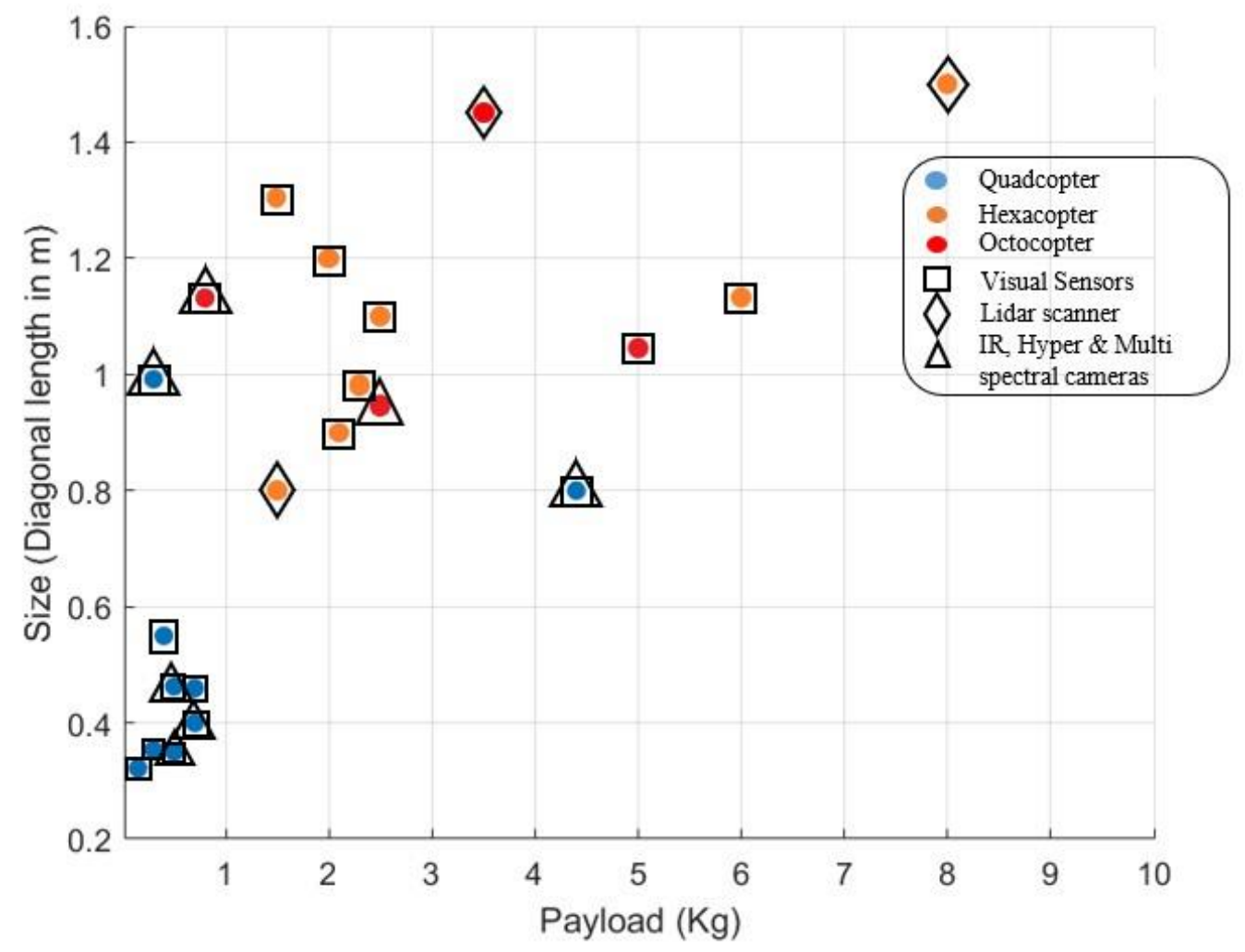

Figure 4. UAV Payload (Kg) vs. Diagonal size of UAV (mm).

\section{Limitations and Opportunities}

UAVs can raise the standards for inspection by retrieving useful bridge data and collecting new bridge data, which was not feasible or economical using traditional bridge inspection practices [87]. However, UAVs present challenges of their own. The reported applications of UAVs on bridge inspections have highlighted some common limitations of current technology. These can be summarized into flight time (endurance), payload, navigation, and sensor (defect type) limitations.

(a) Flight time and payload capacity

Typical flight times of multirotor UAVs, including quadcopters, hexacopters, and octocopters, range from 20 to $30 \mathrm{~min}$ (as shown in Figure 3). The present endurance of UAVs is a major limitation for bridge inspections. A typical long-range visual inspection of a bridge needs multiple battery changes throughout the entire mission that results in increased mission time. Similarly, if during a LiDAR mission the inspection team has to cover the whole inspection area, the low endurance accounts for increased mission time. On the other hand, bridge inspection times vary greatly, from $15 \mathrm{~min}$ to several weeks, and the windy environment can shorten the flight times. Inspections in the under-bridge environment require more careful piloting and, therefore, an exponentially longer time commitment [25].

There is a strong correlation between UAV endurance and payload capacity. Hexacopters and octocopters have an advantage with high payload, but they have limited endurance, and they are unable to navigate during a GPS signal loss. The low endurance limit for these high payload capacity UAVs is a major technological barrier in certain missions like corrosion detection and LiDAR scanning, which require more flight time for evaluating and scanning the targeted area. From Figure 2, we can also see that most of the quadcopters are unable to perform missions that involve using LiDAR sensors due to their low payload capacity. UAV hardware optimization is an efficient way to create a UAV configuration with mission-specific hardware capacities instead of using an off-the-shelf UAV. Overall geometry optimization has been conducted by S.Delbecq et al. [88] and Xunhua 
Dai et al. [89] using a sizing methodology that can provide the optimal UAV configuration based on the mission requirements such as payload capacity, endurance, and altitude.

(b) Navigation and flight in close proximity to structures

Navigating a UAV in congested areas and under bridge decks is challenging with the current technology using GPS signals $[40,86]$. For instance, the Alaska DOT team found that the DJI phantom can lose its position while operating closer to the inspecting surface. This may be due to the interference of the iron reinforced concrete slabs with the magnetometer and internal measurement unit of the UAV. Idaho DOT [30] also had a similar experience using DJI Mavic to inspect under a bridge deck over a river. The aircraft became unstable due to the downward vision sonar signals interfering with flowing water. Such limitations highly restrict the applications of UAVs as a routine inspection tool, and therefore, technologies that allow UAVs to navigate precisely under GPS-denied environments are in high demand. Technical devices that can help to eliminate this problem include real-time kinematic (RTK) equipment to enhance UAV navigation in the GPS-denied environment; collision avoidance sensors (usually a combination of visual, ultrasonic, and radio frequency distance meters); and artificial intelligence and deep learning-based navigation [31]. Quadcopters like the Elios-2 Skyranger R70 have vision-based sensing systems besides GPS positioning, enabling them to keep their path during a GPS signal loss.

Because of the constrained flight environment under bridges, localized aerodynamic flow effects impact both the thrust and stability of the UAVs. This effect varies according to flight profiles and specific bridge characteristics. The number of studies investigating the aerodynamics of multirotors in the proximity of structures is very limited. Christopher mc kinnon et al. [90] discusses the ground effect induced instability in multirotor UAVs, and Sanchez-Cuevas et al. [91] address the "ceiling effect" created when a UAV is flying close to the surface of a structure. Ongoing work to overcome these effects includes developing mathematical models to simulate UAV flight with real-time parameters, which can assist advanced flight control algorithms in counteracting these aerodynamic effects.

(c) Sensors capability in defect detection

Implementing the UAV systems with remote sensing payloads has led to a significant resource-saving in monitoring tasks, but almost all of these inspection methods can only detect surface damages. To perform more in-depth inspections or detect damages inside the structure, NDT methods are required that can be in contact with the structure (i.e., ultrasounds, resistivity meters). Currently, these operations are performed by inspectors that usually employ ladders or lifters, making them rather slow and expensive. As a result, the development of UAV technology to perform contact inspection is a topic of the utmost importance.

RGB and thermal sensors collect spectral reflectance from different wavelengths. Hence there are great radiometric and geometric differences between visible and infrared images. The performance of the vision-based technique is highly affected by the operational conditions, such as the incident angle, illuminance, and undesired contaminants in the air or backgrounds. Moreover, invisible subsurface cracks cannot be detected with the visionbased technique. By contrast, infrared sensors exhibit unique advantages in overcoming adverse light conditions. In particular, the IR techniques are attractive for detecting invisible subsurface and surface delamination. Nevertheless, due to limitations of hardware and environments, infrared images are often accompanied by blurred details, serious noise, and considerably low resolution. Fusion of infrared and visible images is an efficient approach to produce a single image, preserving texture information of both RGB and thermal images and detecting structural cracks with high accuracy $[92,93]$. Table 4 summarizes mission and sensor limitations. 
Table 4. Sensor-specific limitations and current research to address the limitations.

\begin{tabular}{|c|c|c|}
\hline Mission \& Sensors & Observed Limitations & Current Research \\
\hline $\begin{array}{l}\text { 3D model reconstruction } \\
\text { and photogrammetry (LiDAR) }\end{array}$ & $\begin{array}{ll}\text { - } & \text { Weight and price of LiDAR sensors } \\
\text { - } & \text { Additional interpretation is required }\end{array}$ & $\begin{array}{l}\text { Damage mapping to relate the defects to } \\
\text { 3D point cloud [77] }\end{array}$ \\
\hline $\begin{array}{l}\text { Surface crack } \\
\text { detection (RGB) }\end{array}$ & $\begin{array}{l}\text { - } \quad \text { GPS deprived navigation } \\
\text { - } \quad \text { Vibrations and wind } \\
\text { - } \quad \text { 2D ighting condition } \\
\text { positions need to be extracted from each image }\end{array}$ & $\begin{array}{l}\text { Automated image-based crack } \\
\text { detection }[53,94,95]\end{array}$ \\
\hline $\begin{array}{l}\text { Fatigue crack detection } \\
\text { (RGB and IR) }\end{array}$ & $\begin{array}{l}\text { - Low pixel resolution of thermal cameras } \\
\text { High-resolution cameras are not mountable on } \\
\text { UAVs due to weight and are expensive }\end{array}$ & $\begin{array}{l}\text { Autonomous crack segmentation, } \\
\text { deep/machine Generative model to predict } \\
\text { fatigue crack propagation }[11,30,45]\end{array}$ \\
\hline $\begin{array}{l}\text { Delamination and spalling } \\
\text { detection (RGB and IR) }\end{array}$ & $\begin{array}{l}\text { - Delamination is invisible under } \\
\text { visual inspection } \\
\text { - Inspection time effect on the result of } \\
\text { thermal images }\end{array}$ & $\begin{array}{l}\text { Identify depth or thickness of delaminated } \\
\text { areas, artificial intelligence approaches for } \\
\text { automated delamination detection, } \\
\text { Concrete deck condition mapping }[54,58]\end{array}$ \\
\hline Corrosion detection & $\begin{array}{l}\text { A loss of cross-section of the reinforcement } \\
\text { steel typically takes place years before } \\
\text { corrosion products are transported to the outer } \\
\text { concrete surface, where they become apparent } \\
\text { as rust stains }\end{array}$ & $\begin{array}{l}\text { Designing a corrosion inspection UAV for } \\
\text { condition assessments of hardly accessible } \\
\text { parts of structural members }[72,73,96]\end{array}$ \\
\hline
\end{tabular}

\section{Discussion and Conclusions}

UAV-enabled bridge inspection techniques offer a promising alternative to conventional practices. In particular, surface crack detection using RGB cameras, delamination using IRT sensors, and corrosion and fatigue crack detection using a combination of IRT and RGB cameras offer good opportunities for the application of UAVs. Also, large-scale 3D model reconstruction can be conducted by UAVs using Lidar and RGB sensors, and new developments deploy SAR on airborne platforms. The specific requirements for UAVs to conduct these inspections include VTOL capability, sufficient payload capacity to carry mission-specific sensors that range from simple RGB to IR and Multispectral cameras, and LiDAR and SAR sensors. In addition, they need to be capable of flight times typically of $15 \mathrm{~min}$ for short duration missions such as special inspections, and in excess of 30 min for larger-scale bridge surveys or 3D mapping. Last, they need to be able to offer a stable flight platform for the sensors in the vicinity or in contact with the bridge structure.

These mission performance requirements have conditioned the UAV typology used for bridge inspections. Multicopters have been exclusively used in the applications reviewed here, as they offer the simplest and most developed VTOL capability. The analyzed data shows that, within the field of multicopters, quadrotors are primarily used for payloads of $1 \mathrm{~kg}$ or less, and thus most suitable for the lighter sensors such as RGB cameras, as well as IR multispectral and hyperspectral options. They exhibit flight times of 20-25 min and have a frame of up to about $500 \mathrm{~mm}$ diameter. They are also the lowest cost option, with most in the price range of USD 800-1200. Missions that require higher payloads such as LiDAR or SAR sensors (most between about $1 \mathrm{~kg}$ and $6 \mathrm{~kg}$ ) typically rely on larger quadand octocopter drones, with a similar endurance than the quadcopters, however at a larger size (800-1400 mm diagonal frame size), and significantly higher cost between USD 1500 and USD 15,000.

Most of the currently utilized UAVs (especially in the lower price range) are not customdesigned for the mission but rather adaptations of commercially available vehicles. As such, they typically suffer from high payload-endurance sensitivity, navigation difficulties in GPS deprived environments, and flight instabilities in the vicinity of structures. These challenges are being addressed by several thrust areas: 
- $\quad$ Stabilized flight in close proximity to structures and potential in-contact sensing approaches are being explored, potentially augmenting the capabilities of UAVs to execute NDT inspections.

- Artificial Intelligence-supported identification of defects and autonomous navigation also constitutes an area of interest. Computer vision for obstacle identification and navigation in GPS deprived environments further supports these developing autonomous navigation capabilities.

- Overall, vehicle sizing and optimization to maximize endurance and payload capacity are of interest, and a range of optimization techniques such as genetic algorithms are being applied to design specific flight hardware for targeted missions.

Overall, developing UAV technology offers promising perspectives to enhance structural bridge inspection processes. While the available flight vehicle technology is currently still used as a supplemental means for traditional inspections, the potential for future hardware and software developments can introduce novel approaches in inspection methodology.

Author Contributions: Conceptualization, W.A.F., Z.A., Y.A. and E.N.L.; methodology, W.A.F., Z.A., Y.A. and E.N.L.; investigation, Z.A. and Y.A.; writing-original draft preparation, Z.A. and Y.A.; writing-review and editing, Z.A., Y.A., W.A.F. and E.N.L.; supervision, W.A.F. and E.N.L.; project administration, E.N.L.; funding acquisition, E.N.L. and W.A.F. All authors have read and agreed to the published version of the manuscript.

Funding: Funding for this research is provided by the Transportation Infrastructure Durability Center (TIDC) at the University of Maine under grant 69A3551847101 from the U.S. Department of Transportation's University Transportation Centers Program.

Institutional Review Board Statement: Not applicable.

Informed Consent Statement: Not applicable.

Data Availability Statement: The data presented in this study are available on request from the corresponding author. The data sources are publicly available and referenced in the study.

Acknowledgments: The authors wish to acknowledge Dale Peabody of the Maine Department of Transportation and Robert Blunt of VHB for their input on this work.

Conflicts of Interest: The authors declare no conflict of interest.

\section{References}

1. Lei, B.; Ren, Y.; Wang, N.; Huo, L.; Song, G. Design of a New Low-Cost Unmanned Aerial Vehicle and Vision-Based Concrete Crack Inspection Method. Struct. Health Monit. 2020, 19, 1871-1883. [CrossRef]

2. Marchewka, A.; Ziółkowski, P.; Aguilar-Vidal, V. Framework for Structural Health Monitoring of Steel Bridges by Computer Vision. Sensors 2020, 20, 700. [CrossRef] [PubMed]

3. Otero, L.D.; Gagliardo, N. Proof of Concept for Using Unmanned Aerial Vehicles for High Mast Pole and Bridge Inspections; Florida Department of Transportation, Research Center: Tallahassee, FL, USA, 2015.

4. Bridge Condition by Highway System—National Bridge Inventory—Bridge Inspection—Safety-Bridges \& Structures—Federal Highway Administration. Available online: https:/ / www.fhwa.dot.gov/bridge/nbi/no10/condition21.cfm (accessed on 7 December 2021).

5. Ilbeigi, M.; Pawar, B. A Probabilistic Model for Optimal Bridge Inspection Interval. Infrastructures 2020, 5, 47. [CrossRef]

6. Feroz, S.; Abu Dabous, S. UAV-Based Remote Sensing Applications for Bridge Condition Assessment. Remote Sens. 2021, 13, 1809. [CrossRef]

7. ASCE. A Comprehensive Assessment of America's Infrastructre; American Society of Civil Engineers (ASCE): Reston, WV, USA, 2021; p. 172.

8. Nooralishahi, P.; Ibarra-Castanedo, C.; Deane, S.; López, F.; Pant, S.; Genest, M.; Avdelidis, N.P.; Maldague, X.P.V. Drone-Based Non-Destructive Inspection of Industrial Sites: A Review and Case Studies. Drones 2021, 5, 106. [CrossRef]

9. Yaghi, S.R.; Dabous, S.A. State-Of-The Art Practices in Bridge Inspection. Int. J. Civ. Environ. Eng. 2015, 9, $1344-1347$.

10. Abdallah, A.M.; Atadero, R.A.; Ozbek, M.E. A State-of-the-Art Review of Bridge Inspection Planning: Current Situation and Future Needs. J. Bridge Eng. 2022, 27, 03121001. [CrossRef]

11. Morgenthal, G.; Hallermann, N.; Kersten, J.; Taraben, J.; Debus, P.; Helmrich, M.; Rodehorst, V. Framework for Automated UAS-Based Structural Condition Assessment of Bridges. Autom. Constr. 2019, 97, 77-95. [CrossRef] 
12. Yu, K.; Shanthakumar, P.; Orevillo, J.; Bianchi, E.; Hebdon, M.; Tokekar, P. View Planning and Navigation Algorithms for Autonomous Bridge Inspection with UAVs. arXiv 2019, arXiv:191002786.

13. Karim, M.M.; Dagli, C.H.; Qin, R. Modeling and Simulation of a Robotic Bridge Inspection System. Procedia Comput. Sci. 2020, 168, 177-185. [CrossRef]

14. Saleem, M.R.; Park, J.-W.; Lee, J.-H.; Jung, H.-J.; Sarwar, M.Z. Instant Bridge Visual Inspection Using an Unmanned Aerial Vehicle by Image Capturing and Geo-Tagging System and Deep Convolutional Neural Network. Struct. Health Monit. 2021, 20, 1760-1777. [CrossRef]

15. Liu, Y.; Nie, X.; Fan, J.; Liu, X. Image-based Crack Assessment of Bridge Piers Using Unmanned Aerial Vehicles and Threedimensional Scene Reconstruction. Comput.-Aided Civ. Infrastruct. Eng. 2020, 35, 511-529. [CrossRef]

16. Potenza, F.; Rinaldi, C.; Ottaviano, E.; Gattulli, V. A Robotics and Computer-Aided Procedure for Defect Evaluation in Bridge Inspection. J. Civ. Struct. Health Monit. 2020, 10, 471-484. [CrossRef]

17. Whitley, T.; Tomiczek, A.; Tripp, C.; Ortega, A.; Mennu, M.; Bridge, J.; Ifju, P. Design of a Small Unmanned Aircraft System for Bridge Inspections. Sensors 2020, 20, 5358. [CrossRef] [PubMed]

18. Khaloo, A.; Lattanzi, D.; Cunningham, K.; Dell'Andrea, R.; Riley, M. Unmanned Aerial Vehicle Inspection of the Placer River Trail Bridge through Image-Based 3D Modelling. Struct. Infrastruct. Eng. 2018, 14, 124-136. [CrossRef]

19. Zhang, D.; Watson, R.; Dobie, G.; MacLeod, C.; Khan, A.; Pierce, G. Quantifying Impacts on Remote Photogrammetric Inspection Using Unmanned Aerial Vehicles. Eng. Struct. 2020, 209, 109940. [CrossRef]

20. Darby, P.; Hollerman, W.; Miller, J. Exploring the Potential Utility of Unmanned Aerial Vehicles for Practical Bridge Inspection in Louisiana. MATEC Web Conf. 2019, 271, 01001. [CrossRef]

21. Metni, N.; Hamel, T. A UAV for Bridge Inspection: Visual Servoing Control Law with Orientation Limits. Autom. Constr. 2007, 17, 3-10. [CrossRef]

22. Lei, B.; Wang, N.; Xu, P.; Song, G. New Crack Detection Method for Bridge Inspection Using UAV Incorporating Image Processing. J. Aerosp. Eng. 2018, 31, 04018058. [CrossRef]

23. National Bridge Inspection Standards; Federal Highway Administration, Department of Transportation. 2004. Available online: https://www.govinfo.gov/content/pkg/FR-2004-12-14/pdf/04-27355.pdf (accessed on 1 April 2004).

24. Tomiczek, A.P.; Whitley, T.J.; Bridge, J.A.; Ifju, P.G. Bridge Inspections with Small Unmanned Aircraft Systems: Case Studies. J. Bridge Eng. 2019, 24, 05019003. [CrossRef]

25. Dorafshan, S.; Thomas, R.J.; Coopmans, C.; Maguire, M. A Practitioner's Guide to Small Unmanned Aerial Systems for Bridge Inspection. Infrastructures 2019, 4, 72. [CrossRef]

26. Jeong, E.; Seo, J.; Wacker, J. Literature Review and Technical Survey on Bridge Inspection Using Unmanned Aerial Vehicles. J. Perform. Constr. Facil. 2020, 34, 04020113. [CrossRef]

27. Moller, P.S. Caltrans Bridge Inspection Aerial Robot Final Report; University of California at Davis: Davis, CA, USA, 2008 ; p. 33.

28. Duque, L.; Seo, J.; Wacker, J. Synthesis of Unmanned Aerial Vehicle Applications for Infrastructures. J. Perform. Constr. Facil. 2018, 32, 04018046. [CrossRef]

29. Baker, M. UAS Bridge Inspection Pilot; Wisconsin Department of Transportation: Madison, WI, USA, 2017.

30. Dorafshan, S.; Maguire, M.; Hoffer, N.; Coopmans, C. Fatigue Crack Detection Using Unmanned Aerial Systems in UnderBridge Inspection. 2017; undefined. Available online: https://www.semanticscholar.org/paper/Fatigue-Crack-Detection-UsingUnmanned-Aerial-in-Dorafshan-Maguire/ba0a53bb697b58f7fa8c61654b7556dfc754a290 (accessed on 29 October 2021).

31. Plotnikov, M.; Collura, J. Integrating Unmanned Aircraft Systems into State Department of Transportation Highway Bridge Inspection Procedures: Challenges, Implications, and Lessons Learned. Transp. Res. Rec. J. Transp. Res. Board 2021, 2676, 036119812110444. [CrossRef]

32. Brooks, C.; Dobson, R.J.; Dean, D.B.; Banach, D.; Oommen, T.; Havens, T.; Ahlborn, T.; Cook, S.J.; Clover, A. Evaluating the Use of Unmanned Aerial Vehicles for Transportation Purposes: A Michigan Demonstration; Michigan Department of Transportation: Lansing, MI, USA, 2014.

33. Gillins, D.T.; Parrish, C.; Gillins, M.N.; Simpson, C. Eyes in the Sky: Bridge Inspections with Unmanned Aerial Vehicles; Oregon Department of Transportation: Salem, OR, USA, 2018.

34. Lovelace, B.; Wells, J.L. Improving the Quality of Bridge Inspections Using Unmanned Aircraft Systems (UAS); Minnesota Department of Transportation: St. Paul, MN, USA, 2018; p. 345.

35. Plotnikov, M.; Ni, D.; Price, D. The Application of Unmanned Aerial Systems In Surface Transportation-Volume II-A: Development of a Pilot Program to Integrate UAS Technology to Bridge and Rail Inspections; Massachusetts Department of Transportation: Boston, MA, USA, 2019; p. 74.

36. McGuire, M.; Rys, M.J.; Rys, A. A Study of How Unmanned Aircraft Systems Can Support the Kansas Department of Transportation's Efforts to Improve Efficiency, Safety, and Cost Reduction: Final Report; Kansas Department of Transportation: Manhattan, KS, USA, 2016.

37. Daly, M. NDOT Explores Unmanned Aerial Vehicle Bridge Inspection. The Roadrunner; Nebraska Department of Transportation: Lincoln, NE, USA, 2018.

38. Zajkowski, T.; Snyder, K.; Arnold, E.; Divakaran, D.; North Carolina State University. Institute for Transportation Research \& Education; NextGen Air Transportation Consortium Unmanned Aircraft Systems: A New Tool for DOT Inspections: Final Report. 2016. Available online: https:/ / rosap.ntl.bts.gov/view/dot/32892 (accessed on 22 January 2022). 
39. O'Neill-Dunne, J. Unmanned Aircraft Systems for Transportation Decision Support; University of Vermont: Burlington, VT, USA, 2016.

40. Dorafshan, S.; Maguire, M.; Hoffer, N.V.; Coopmans, C.; Thomas, R.J.; Utah State University. Department of Civil and Environmental Engineering. In Unmanned Aerial Vehicle Augmented Bridge Inspection Feasibility Study; Utah State University: Logan, UT, USA, 2017; p. 177.

41. Morehouse, C. Technology for Alaskan Transportation; Alaska Department of Trasportation: Fairbanks, AK, USA, 2016 ; p. 9.

42. Burgett, J.M.; Bausman, D.; Comert, G. Unmanned Aircraft Systems (UAS) Impact on Operational Efficiency and Connectivity; Center for Connected Multimodal Mobility: Clemson, SC, USA, 2019; p. 86.

43. Seo, J.; Duque, L.; Wacker, J. Drone-Enabled Bridge Inspection Methodology and Application. Autom. Constr. 2018, 94, 112-126. [CrossRef]

44. Sankarasrinivasan, S.; Balasubramanian, E.; Karthik, K.; Chandrasekar, U.; Gupta, R. Health Monitoring of Civil Structures with Integrated UAV and Image Processing System. Procedia Comput. Sci. 2015, 54, 508-515. [CrossRef]

45. Ayele, Y.Z.; Aliyari, M.; Griffiths, D.; Droguett, E.L. Automatic Crack Segmentation for UAV-Assisted Bridge Inspection. Energies 2020, 13, 6250. [CrossRef]

46. Chen, J.; Wu, J.; Chen, G.; Dong, W.; Sheng, X. Design and Development of a Multi-Rotor Unmanned Aerial Vehicle System for Bridge Inspection. In Intelligent Robotics and Applications; Kubota, N., Kiguchi, K., Liu, H., Obo, T., Eds.; Lecture Notes in Computer Science; Springer International Publishing: Cham, Switzerland, 2016; Volume 9834, pp. 498-510. ISBN 978-3-319-43505-3.

47. Roca, D.; Lagüela, S.; Díaz-Vilariño, L.; Armesto, J.; Arias, P. Low-Cost Aerial Unit for Outdoor Inspection of Building Façades. Autom. Constr. 2013, 36, 128-135. [CrossRef]

48. HekmatiAthar, S.; Goudarzi, N.; Karimoddini, A.; Homaifar, A.; Divakaran, D. A Systematic Evaluation and Selection of UAS-Enabled Solutions for Bridge Inspection Practices. In Proceedings of the 2020 IEEE Aerospace Conference, Big Sky, MT, USA, 7 March 2020; pp. 1-11.

49. Bolourian, N.; Hammad, A. LiDAR-Equipped UAV Path Planning Considering Potential Locations of Defects for Bridge Inspection. Autom. Constr. 2020, 117, 103250. [CrossRef]

50. Jung, S.; Choi, D.; Song, S.; Myung, H. Bridge Inspection Using Unmanned Aerial Vehicle Based on HG-SLAM: Hierarchical Graph-Based SLAM. Remote Sens. 2020, 12, 3022. [CrossRef]

51. Spencer, B.F.; Hoskere, V.; Narazaki, Y. Advances in Computer Vision-Based Civil Infrastructure Inspection and Monitoring. Engineering 2019, 5, 199-222. [CrossRef]

52. Bhowmick, S.; Nagarajaiah, S.; Veeraraghavan, A. Vision and Deep Learning-Based Algorithms to Detect and Quantify Cracks on Concrete Surfaces from UAV Videos. Sensors 2020, 20, 6299. [CrossRef] [PubMed]

53. Chaiyasarn, K.; Khan, W.; Ali, L.; Sharma, M.; Brackenbury, D.; Dejong, M. Crack Detection in Masonry Structures Using Convolutional Neural Networks and Support Vector Machines. In Proceedings of the 35th ISARC, Berlin, Germany, 20-25 July 2018; pp. 118-125.

54. Omar, T.; Nehdi, M.L. Remote Sensing of Concrete Bridge Decks Using Unmanned Aerial Vehicle Infrared Thermography. Autom. Constr. 2017, 83, 360-371. [CrossRef]

55. Mac, V.H.; Tran, Q.H.; Huh, J.; Doan, N.S.; Kang, C.; Han, D. Detection of Delamination with Various Width-to-Depth Ratios in Concrete Bridge Deck Using Passive IRT: Limits and Applicability. Materials 2019, 12, 3996. [CrossRef]

56. Hiasa, S.; Birgul, R.; Necati Catbas, F. A Data Processing Methodology for Infrared Thermography Images of Concrete Bridges. Comput. Struct. 2017, 190, 205-218. [CrossRef]

57. Washer, G.; Fenwick, R.; Bolleni, N. Effects of Solar Loading on Infrared Imaging of Subsurface Features in Concrete. J. Bridge Eng. 2010, 15, 384-390. [CrossRef]

58. Ellenberg, A.; Kontsos, A.; Moon, F.; Bartoli, I. Bridge Deck Delamination Identification from Unmanned Aerial Vehicle Infrared Imagery. Autom. Constr. 2016, 72, 155-165. [CrossRef]

59. Shen, Z.; Cheng, C.; Na, R.; Shang, Z. To Automate Detecting, Quantifying and Mapping of Delamination via Arial Thermography; Nebraska Department of Transportation: Lincoln, NE, USA, 2020; p. 44.

60. Youn, W.; Ko, H.; Choi, H.; Choi, I.; Baek, J.-H.; Myung, H. Collision-Free Autonomous Navigation of A Small UAV Using Low-Cost Sensors in GPS-Denied Environments. Int. J. Control Autom. Syst. 2021, 19, 953-968. [CrossRef]

61. Mebarki, R.; Lippiello, V.; Siciliano, B. Nonlinear Visual Control of Unmanned Aerial Vehicles in GPS-Denied Environments. IEEE Trans. Robot. 2015, 31, 1004-1017. [CrossRef]

62. Chowdhary, G.; Johnson, E.N.; Magree, D.; Wu, A.; Shein, A. GPS-Denied Indoor and Outdoor Monocular Vision Aided Navigation and Control of Unmanned Aircraft. J. Field Robot. 2013, 30, 415-438. [CrossRef]

63. Dehbi, Y.; Klingbeil, L.; Plümer, L. UAV mission planning for automatic exploration and semantic mapping. Int. Arch. Photogramm. Remote Sens. Spat. Inf. Sci. 2020, XLIII-B1-2020, 521-526. [CrossRef]

64. González-deSantos, L.M.; Martínez-Sánchez, J.; González-Jorge, H.; Navarro-Medina, F.; Arias, P. UAV Payload with Collision Mitigation for Contact Inspection. Autom. Constr. 2020, 115, 103200. [CrossRef]

65. Myeong, W.C.; Jung, K.Y.; Jung, S.W.; Jung, Y.H.; Myung, H. Development of a Drone-Type Wall-Sticking and Climbing Robot. In Proceedings of the 2015 12th International Conference on Ubiquitous Robots and Ambient Intelligence (URAI), Goyang, Korea, 28 October 2015; pp. 386-389.

66. Kocer, B.B.; Tjahjowidodo, T.; Pratama, M.; Seet, G.G.L. Inspection-While-Flying: An Autonomous Contact-Based Nondestructive Test Using UAV-Tools. Autom. Constr. 2019, 106, 102895. [CrossRef] 
67. Sreenath, S.; Malik, H.; Husnu, N.; Kalaichelavan, K. Assessment and Use of Unmanned Aerial Vehicle for Civil Structural Health Monitoring. Procedia Comput. Sci. 2020, 170, 656-663. [CrossRef]

68. Gucunski, N.; Imani, A.; Romero, F.; Nazarian, S.; Yuan, D.; Wiggenhauser, H.; Shokouhi, P.; Taffe, A.; Kutrubes, D. Nondestructive Testing to Identify Concrete Bridge Deck Deterioration; Transportation Research Board: Washington, DC, USA, 2013; ISBN 978-0-30912933-6.

69. Cheng, C.; Shang, Z.; Shen, Z. Automatic Delamination Segmentation for Bridge Deck Based on Encoder-Decoder Deep Learning through UAV-Based Thermography. NDT E Int. 2020, 116, 102341. [CrossRef]

70. Tomita, K.; Chew, M.Y.L. A Review of Infrared Thermography for Delamination Detection on Infrastructures and Buildings. Sensors 2022, 22, 423. [CrossRef]

71. Rahman, A.; Wu, Z.Y.; Kalfarisi, R. Semantic Deep Learning Integrated with RGB Feature-Based Rule Optimization for Facility Surface Corrosion Detection and Evaluation. J. Comput. Civ. Eng. 2021, 35, 04021018. [CrossRef]

72. Chen, Q.; Wen, X.; Lu, S.; Sun, D. Corrosion Detection for Large Steel Structure Base on UAV Integrated with Image Processing System. IOP Conf. Ser. Mater. Sci. Eng. 2019, 608, 012020. [CrossRef]

73. Pfändler, P.; Bodie, K.; Angst, U.; Siegwart, R. Flying Corrosion Inspection Robot for Corrosion Monitoring of Civil StructuresFirst Results. In Proceedings of the SMAR 2019-Fifth Conference on Smart Monitoring, Assessment and Rehabilitation of Civil Structures-Program, Potsdam, Germany, 27-29 August 2019.

74. Pryor, G. Utilizing Unmanned Aerial Vehicles (UAVs) for the Estimation of Beam Corrosion of Steel Bridge Girders. Master's Thesis, University of Massachusetts Amherst, Amherst, MA, USA, 2021.

75. Dorafshan, S.; Campbell, L.E.; Maguire, M.; Connor, R.J. Benchmarking Unmanned Aerial Systems-Assisted Inspection of Steel Bridges for Fatigue Cracks. J. Transp. Res. Board 2021, 2675, 154-166. [CrossRef]

76. Chen, S.; Laefer, D.F.; Mangina, E.; Zolanvari, S.M.I.; Byrne, J. UAV Bridge Inspection through Evaluated 3D Reconstructions. J. Bridge Eng. 2019, 24, 05019001. [CrossRef]

77. Perry, B.J.; Guo, Y.; Atadero, R.; van de Lindt, J.W. Streamlined Bridge Inspection System Utilizing Unmanned Aerial Vehicles (UAVs) and Machine Learning. Measurement 2020, 164, 108048. [CrossRef]

78. Kakillioglu, B.; Wang, J.; Velipasalar, S.; Janani, A.; Koch, E. 3D Sensor-Based UAV Localization for Bridge Inspection. In Proceedings of the 2019 53rd Asilomar Conference on Signals, Systems and Computers, Pacific Grove, CA, USA, 3 November 2019; pp. 1926-1930.

79. Balamurugan, G.; Valarmathi, J.; Naidu, V.P.S. Survey on UAV Navigation in GPS Denied Environments. In Proceedings of the 2016 International Conference on Signal Processing, Communication, Power and Embedded System (SCOPES), Paralakhemundi, Odisha, India, 3-5 October 2016; pp. 198-204.

80. Vanegas, F.; Gaston, K.J.; Roberts, J.; Gonzalez, F. A Framework for UAV Navigation and Exploration in GPS-Denied Environments. In Proceedings of the 2019 IEEE Aerospace Conference, Big Sky, MT, USA, 2-9 March 2019; pp. 1-6.

81. Yoon, H.; Wan, W.; Kim, H.; Hovakimyan, N.; Sha, L.; Voulgaris, P.G. Towards Resilient UAV: Escape Time in GPS Denied Environment with Sensor Drift. IFAC Pap. 2019, 52, 423-428. [CrossRef]

82. Hubbard, B.; Hubbard, S. Unmanned Aircraft Systems (UAS) for Bridge Inspection Safety. Drones 2020, 4, 40. [CrossRef]

83. Jung, S.; Song, S.; Kim, S.; Park, J.; Her, J.; Roh, K.; Myung, H. Toward Autonomous Bridge Inspection: A Framework and Experimental Results. In Proceedings of the 2019 16th International Conference on Ubiquitous Robots (UR), Jeju, Korea, 24-27 June 2019; pp. 208-211.

84. Dorafshan, S.; Maguire, M. Bridge Inspection: Human Performance, Unmanned Aerial Systems and Automation. J. Civ. Struct. Health Monit. 2018, 8, 443-476. [CrossRef]

85. Lort, M.; Aguasca, A.; López-Martínez, C.; Marín, T.M. Initial Evaluation of SAR Capabilities in UAV Multicopter Platforms. IEEE J. Sel. Top. Appl. Earth Obs. Remote Sens. 2018, 11, 127-140. [CrossRef]

86. Lovelace, B.; Zink, J. Unmanned Aerial Vehicle Bridge Inspection Demonstration Project; Minnesota Department of Transportation: St. Paul, MN, USA, 2015; p. 214.

87. Bianchi, E.; Abbott, A.L.; Tokekar, P.; Hebdon, M. COCO-Bridge: Structural Detail Data Set for Bridge Inspections. J. Comput. Civ. Eng. 2021, 35, 04021003. [CrossRef]

88. Delbecq, S.; Budinger, M.; Ochotorena, A.; Reysset, A.; Defay, F. Efficient Sizing and Optimization of Multirotor Drones Based on Scaling Laws and Similarity Models. Aerosp. Sci. Technol. 2020, 102, 105873. [CrossRef]

89. Dai, X.; Quan, Q.; Cai, K.-Y. Design Automation and Optimization Methodology for Electric Multicopter UAVs. arXiv 2019, arXiv:1908.06301.

90. McKinnon, C.D.; Schoellig, A.P. Estimating and Reacting to Forces and Torques Resulting from Common Aerodynamic Disturbances Acting on Quadrotors. Robot. Auton. Syst. 2020, 123, 103314. [CrossRef]

91. Sanchez-Cuevas, P.; Ramon-Soria, P.; Arrue, B.; Ollero, A.; Heredia, G. Robotic System for Inspection by Contact of Bridge Beams Using UAVs. Sensors 2019, 19, 305. [CrossRef] [PubMed]

92. Zhu, R.; Yu, D.; Ji, S.; Lu, M. Matching RGB and Infrared Remote Sensing Images with Densely-Connected Convolutional Neural Networks. Remote Sens. 2019, 11, 2836. [CrossRef]

93. Jin Lim, H.; Hwang, S.; Kim, H.; Sohn, H. Steel Bridge Corrosion Inspection with Combined Vision and Thermographic Images. Struct. Health Monit. 2021, 20, 3424-3435. [CrossRef] 
94. Dung, C.V.; Sekiya, H.; Hirano, S.; Okatani, T.; Miki, C. A Vision-Based Method for Crack Detection in Gusset Plate Welded Joints of Steel Bridges Using Deep Convolutional Neural Networks. Autom. Constr. 2019, 102, 217-229. [CrossRef]

95. Kim, B.; Cho, S. Image-based Concrete Crack Assessment Using Mask and Region-based Convolutional Neural Network. Struct. Control Health Monit. 2019, 26, e2381. [CrossRef]

96. Henrickson, J.V.; Rogers, C.; Lu, H.-H.; Valasek, J.; Shi, Y. Infrastructure Assessment with Small Unmanned Aircraft Systems. In Proceedings of the 2016 International Conference on Unmanned Aircraft Systems (ICUAS), Arlington, VA, USA, 7-10 June 2016; pp. 933-942. 